\title{
Crescimento econômico, padrões de especialização e industrialização: um estudo comparativo das exportações do BRIC
}

\section{Economic growth, patterns of specialization and industrialization: a comparative study of BRIC exports (1980-2013)}

André Luís Cabral de Lourenço - Doutor em Economia pela Universidade Federal do Rio de Janeiro e mestre em Ciência Econômica pela Univerdade Estadual de Campinas (UNICAMP). Professor associado da Universidade Federal do Rio Grande do Norte (UFRN). E-mail: andre.lclourenco@gmail.com

Franciane Alves Cardoso - Mestre em Ciências Econômicas pela Universidade Federal do Rio Grande do Norte (UFRN). E-mail: franufrn_05@yahoo.com.br

\section{Resumo}

Compara-se, neste artigo, o desempenho dos países componentes do BRIC (Brasil, China, Índia e Rússia) no período 1980-2013, visando compreender melhor o papel dos padrões de especialização (em particular das exportações) no desempenho díspar em termos de crescimento do Brasil em relação aos demais membros do grupo. As principais conclusões do trabalho são: 1) As taxas de crescimento relativas dessas economias estiveram estreitamente associadas às respectivas razões entre as elasticidades-renda da demanda por exportações e por importações, de forma consistente com o sugerido pelo modelo de crescimento de Thirlwall; 2) Os países que cresceram mais rapidamente entre os do grupo são os que menos perderam participação tanto do setor industrial em geral quanto especificamente da indústria de transformação no valor agregado, de forma consistente com o tratamento teórico de Kaldor.

\section{Palavras-chave}

BRIC. Crescimento. Especialização. Indústria. Exportações.

\begin{abstract}
The paper compares the performance of the BRIC countries (Brazil, China, India and Russian Federation) in the period 1980-2013, to better understand the role of specialization patterns (particularly exports) in disparate performance in terms of growth of Brazil in relation to other group members. The main conclusions are: 1) The growth rates for these economies were closely associated with the respective ratio between the income elasticities of demand for exports and imports, consistently with Thirlwall's growth model; 2) The countries that grew faster among the group are the ones that lost least share of the industrial sector in general and specifically of the manufacturing industry in aggregate value, in a way consistent with the theoretical treatment of Kaldor.
\end{abstract}

\section{Keywords}

BRIC. Growth. Specialization. Manufacturing. Exports. 


\section{INTRODUÇÃO}

Nos últimos anos o BRIC ${ }^{1}$ - sigla do grupo de países ao qual pertencem Brasil, Rússia, Índia e China - vem ganhando destaque no cenário internacional, tanto no âmbito econômico quanto em termos de influência geopolítica. Embora não se trate de um bloco econômico, este agrupamento, antes apenas citado nos meios acadêmicos, tem motivado a discussão sobre a relevância de acordos bilaterais e multilaterais no âmbito da política internacional.

Como observa Fiori (2007), contudo, o grupo é composto por países altamente heterogêneos sob variados aspectos. Historicamente, sua formação é muito diversa: um antigo Império "excêntrico" oriental, outrora a grande potência mundial, agora "reemergente" e semi-socialista; um ex-Império de passado servil e ex-socialista; e duas ex-colônias de exploração, uma herdeira do antigo "modo de produção asiático", e a outra como antiga plantation escravista. Geopoliticamente, enquanto Rússia e China adentram o século XXI como integrantes da cúpula do sistema interestatal, Brasil e Índia permanecem relegados à condição de potências regionais. Economicamente, a dispersão dos níveis de desenvolvimento pode ser claramente observada a partir das respectivas rendas per capita. Medidas em poder de compra constante, a Rússia é a $58^{a}$ no ranking, com cerca de US $\$ 17,9$ mil; o Brasil $\left(79^{\circ}\right)$ possui US $\$ 12,2$ mil; a China $\left(93^{\mathrm{a}}\right)$, US $\$ 9,8$ mil; e a Índia $\left(133^{\mathrm{a}}\right)$, US $\$ 4,1$ mill $^{2}$. Também são muito heterogêneos seus indicadores sociais ${ }^{3}$.

Entretanto, os países que compõem este grupo, além de considerados em desenvolvimento, apresentam algumas semelhanças quando observadas as dimensões territoriais, as elevadas taxas de crescimento do Produto Interno Bruto (PIB) e o crescente peso que suas economias assumiram na economia mundial durante a década passada (BAUMANN; ARAÚJO; FERREIRA, 2010). Em particular, são os únicos países em desenvolvimento entre as nove maiores economias mundiais.

Nos anos 2000, tais países tiveram ampla contribuição na elevação da produção mundial, ajudando a reduzir os efeitos da crise financeira global iniciada em 2007/8, que atingiu principalmente os países desenvolvidos. Entretanto, no início desta década, o desempenho do PIB destes países apresentou brusca

\footnotetext{
Termo formulado por Jim O`Neill (2001), diretor da Goldman Sachs. Ressalta-se que a África de Sul não foi incluída na análise, com a consequente exclusão do "S" dos BRICS. Justifica-se tal procedimento pelo fato de que, embora subdesenvolvida e no mínimo potência regional, ela é apenas o $25^{\circ}$ país no ranking dos PIBs, enquanto todos os demais países considerados na análise estão entre as 7 maiores economias.

FMI (2014).

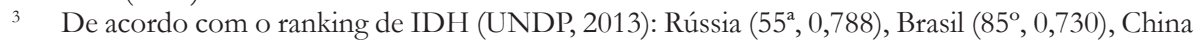
(101 $\left.{ }^{\mathrm{a}}, 0,699\right)$, e Índia $\left(136^{\mathrm{a}}, 0,554\right)$.
} 
desaceleração. Contudo, ainda não se sabe se este movimento é apenas temporário, ou algo duradouro (THE ECONOMIST, 2013).

A trajetória de crescimento vivenciada pela China (com maior destaque) e pela Índia nos últimos 30 anos desperta interesse de muitos estudiosos, visto que na década de 1970, a China cresceu em média 5\% ao ano (a.a), ao passo que no período entre 2001 e 2010 este saltou para cerca de 11\%. Já a Índia, que cresceu aproximadamente $3 \%$ a.a na década de 1970, apresentou crescimento médio de 7,8\% a.a no período entre 2001 e 2010.

No tocante a Rússia, sua trajetória de crescimento foi ainda mais distinta das demais, na medida em que saltou de uma taxa média negativa (de -3,6\% a.a) no período pós-dissolução da União Soviética, na década de 1990, para uma média de 5\% a.a no período 2001-2010.

Estes "saltos" na trajetória de crescimento contrastam significativamente com o movimento oposto ocorrido no Brasil. No período entre 1890 e 1980, o crescimento do PIB brasileiro mostrou-se bastante significativo, sendo considerada por Maddison (2001) como a economia que apresentou a maior taxa de crescimento quando comparada às demais nações. Ao considerar-se apenas a década de 1970, esta taxa foi de 8,5\% anual.

Porém, o declínio da taxa de crescimento no período de 1980 a 2000 para um valor próximo a um terço da média anterior marca uma importante perda de posição relativa perante os demais países. Na década de 1980, o Brasil registrou um crescimento do PIB real médio de apenas 1,7\% anual. Em que pesem as enormes diferenças estruturais que envolvem essas economias, o estudo desse movimento tão contrastante pode trazer maior compreensão acerca da trajetória nacional.

Gráfico 1 - Taxa de crescimento do PIB real (em \%); BRIC, 1990-2012

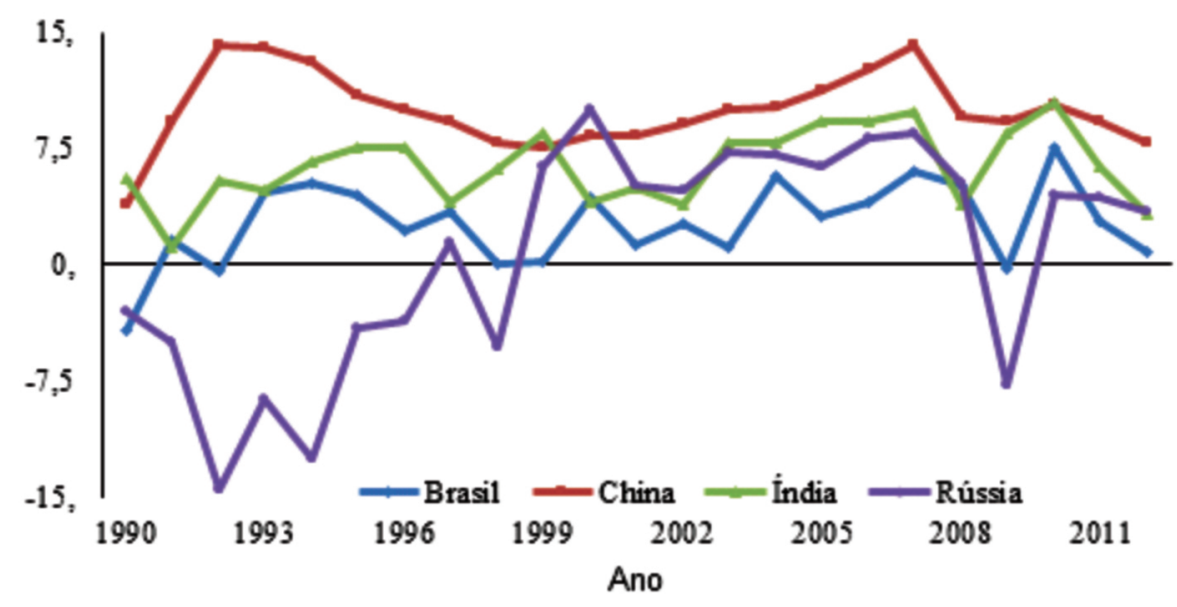

Fonte: World Development Indicators Database (2013). 
Observa-se a partir de 2009, conforme exposto no Gráfico 2, uma desaceleração das taxas de crescimento de todos os BRIC, com exceção do ano de 2010. O curso de crescimento da década passada apontava para os possíveis sinais de retorno do crescimento brasileiro às taxas seculares. Entretanto, a desaceleração mais recente faz-nos lembrar dos problemas enfrentados pelo Brasil para manter um crescimento robusto e sustentável.

A partir do Gráfico 1, parece ainda correto afirmar que as divergências nas taxas de crescimento não constituem exclusividade da relação entre os países desenvolvidos e os em desenvolvimento. Tal divergência ocorre também entre os próprios países em desenvolvimento, como no caso dos BRIC. Neste contexto, o objetivo central deste ensaio é observar o padrão de especialização destas economias, com foco no papel das exportações para o desenvolvimento econômico, entre 1980 e 2012.

Tem-se por hipótese a ideia de que os países que melhor utilizaram as exportações como componente estratégico da política de desenvolvimento (em particular, no sentido de promoverem transformação estrutural em prol de setores produtivos mais sofisticados) obtiveram melhoria na restrição externa e no próprio desempenho em termos de crescimento.

A justificativa deste estudo consiste na importância de compreender as semelhanças e diferenças entre os BRIC, dada a relevância que tais economias vêm adquirindo no âmbito internacional e suas elevadas taxas de crescimento nas últimas duas décadas.

A metodologia utilizada consiste na pesquisa explicativa de delineamento bibliográfico e documental. As fontes dos dados são secundárias, retiradas principalmente da UNCTAD (2013) e do World Development Indicators Online (2013).

O presente trabalho possui quatro seções, incluindo esta introdução. $\mathrm{Na}$ próxima seção discute-se o pensamento de Prebisch (1949) e Singer (1950), onde a industrialização é vista como "elemento propulsor do desenvolvimento econômico", as contribuições heterodoxas à teoria do desenvolvimento, bem como as contribuições atuais em defesa da industrialização para reduzir a vulnerabilidade externa. $\mathrm{Na}$ terceira seção faz-se uma análise da importância do setor industrial para os países que pertencem ao BRIC e a relevância da composição das exportações como forma de auferirem maiores taxas de crescimento. Breves considerações finais compõem a quarta e última seção. 


\section{COMÉRCIO INTERNACIONAL E PADRÕES DE ESPECIALIZA- ÇÃO: PRECURSORES DA IDEIA DA INDUSTRIALIZAÇÃO COMO "ELEMENTO PROPULSOR DO DESENVOLVIMENTO ECONÔMICO"}

A importância do comércio internacional para o crescimento econômico é objeto de discussão desde os primórdios mercantilistas, passando pelos economistas clássicos como Smith (1985) e Ricardo (1965) e prosseguindo até os dias de hoje. O padrão de especialização constitui-se um dos determinantes básicos da inserção externa de uma economia no comércio internacional. A construção de uma inserção adequada, por sua vez, como se arguirá, é um componente fundamental de uma estratégia vitoriosa de desenvolvimento.

Diferentemente do que propõe a corrente convencional, as ideias exploradas nas linhas seguintes questionam a capacidade dos mecanismos equilibradores proporcionados pela livre operação dos mecanismos de mercado conduzir as economias ao equilíbrio dos respectivos Saldos em Transações Correntes (STC) sem afetar permanentemente seu crescimento. Assim, de acordo com o referencial teórico aqui adotado, existe a possibilidade de que tais mecanismos promovam o crescimento do Passivo Externo Líquido (PEL) por trajetórias insustentáveis, ocasionando eventualmente uma crise de endividamento externo de graves consequências.

Para o pensamento neoclássico, porém, os preços relativos refletem adequadamente o grau de escassez dos fatores de produção, bem como opera o princípio da plena substituição destes fatores. Em conjunto com as propriedades de retornos constantes de escala e de rendimentos marginais decrescentes dos fatores, tais hipóteses teóricas suportam a existência de uma tendência à convergência da renda per capita de todos os países do mundo em estado estacionário, como em Solow (1956). Jones (2000) encontra evidências empíricas favoráveis a esta tendência, mas seu estudo é muito controverso, e vários autores ortodoxos parecem mais dispostos a admitir que a convergência incondicional só ocorre de fato no "clube" dos países mais desenvolvidos, mas não entre esses e os subdesenvolvidos ${ }^{4}$. Abre-se assim espaço para abordagens alternativas, tanto no pensamento convencional quanto alhures.

$\mathrm{Na}$ abordagem exposta nesta seção apresentam-se os argumentos heterodoxos a favor da tendência oposta, qual seja, de que a polarização entre as taxas de crescimento de países e regiões é o resultado esperado da livre operação dos mecanismos de mercado.. O desenvolvimento do argumento remete aos primórdios do desenvolvimentismo, em particular às contribuições de

\footnotetext{
$4 \quad$ Vide Carlin e Soskice (2006) para trabalhos empíricos neste sentido.
} 
Prebisch (1949), Singer (1950) e Furtado (1961, 1983), entre outros. A chave da compreensão do subdesenvolvimento repousa em seu padrão de especialização. Países subdesenvolvidos, com uma estrutura produtiva relativamente atrasada, apresentam tendência à especialização na produção e exportação de bens de baixo conteúdo inovativo e tecnológico, e propensão a importar produtos mais intensivos em tecnologia, que apresentam alta elasticidade-renda.

No que concerne ao progresso técnico, argumentava-se que favorecia produtos com elasticidade-renda da demanda mais elevada (na época, as manufaturas). $\mathrm{Na}$ medida em que países subdesenvolvidos importam produtos de maior intensidade tecnológica, perdem a oportunidade de se apropriar dos ganhos do progresso tecnológico. Resulta uma tendência secular de piora dos termos de troca que faz com que os efeitos do progresso técnico sejam transferidos aos países já desenvolvidos.

O desenvolvimento industrial foi então visto como caminho inevitável para o desenvolvimento econômico e social, considerando a indústria como "elemento propulsor do desenvolvimento", na medida em que acelera o progresso técnico incorporado nas máquinas e equipamentos e propicia a retenção dos ganhos dele originários.

\section{CONTRIBUIÇÕESHETERODOXASÀTEORIADOCRESCIMENTO RESTRINGIDO PELO BALANÇO DE PAGAMENTOS}

A teoria heterodoxa do crescimento econômico recebeu expressiva contribuição no trabalho de'Thirlwall(1979), particularmente no sentido de modelar algumas das ideias desenvolvimentistas, bem como em testá-las empiricamente. A restrição externa ao crescimento das economias em desenvolvimento foi o foco de sua análise, assim como a explicação das divergências entre as taxas de crescimento dos países. Segundo o autor, as elasticidades-renda das exportações e das importações têm um papel fundamental na explicação da tendência à polarização verificada nestas economias, bem como das políticas necessárias para a suavização de tais restrições.

Neste contexto, nos países periféricos, a restrição do balanço de pagamentos seria o maior obstáculo encontrado ao crescimento. Contudo, é preciso observar que o balanço de pagamentos atua como elemento de restrição em um contexto no qual o produto é impulsionado pela demanda agregada. Trata-se assim de um modelo demand-led, no qual a restrição operacional imediata não é a disponibilidade 
física de fatores de produção ${ }^{5}$, mas sim de divisas. Ademais, ao assumir a validade da hipótese de paridade de poder de compra no longo prazo, fica descartada a possibilidade de operação da taxa de câmbio real como elemento equilibrador do balanço de pagamentos. É o próprio crescimento econômico portanto que precisa ser ajustado para, via efeito renda, impedir a eclosão de crises de balanço de pagamentos e dos cenários inflacionários a elas tipicamente associados.

Grosso modo, Thirlwall apresenta um modelo teórico no qual a taxa máxima de crescimento de longo prazo $\left(\mathrm{g}_{\mathrm{BP}}\right)$ é dada pela taxa de crescimento do produto mundial ${ }^{6}$ (z), multiplicada pela elasticidade-renda da demanda por exportações $(\varepsilon)$ e dividida pela elasticidade-renda da demanda por importações $(\pi)$ :

$$
\mathrm{g}_{\mathrm{BP}}=\frac{\varepsilon}{\pi} \mathrm{z}
$$

Considerando exógena a taxa de crescimento do produto mundial, as variáveis chave para a execução da política econômica são as elasticidades-renda da demanda por exportações e por importações.

O cerne da contribuição de Thirlwall é a explicação da restrição ao crescimento econômico. Caso uma economia insista em crescer acima do limite possibilitado pela sustentabilidade de suas contas externas, no longo prazo haveria uma escassez de divisas, sendo necessário recorrer a empréstimos externos consecutivos e crescentes. Assim, existiriam países que precisariam conter seu crescimento em decorrência desta restrição, mesmo apresentando capacidade ociosa e mão-de-obra excedente. Há, pois, um limite relativo ao déficit em transações correntes, além do qual os mercados financeiros se inquietam e o país ficaria impossibilitado de atrair mais financiamento externo (THIRLWALL, 2005). Nesta análise, o conteúdo das exportações é relevante e sua elasticidaderenda (determinada pela estrutura produtiva de cada país) pode restringir a obtenção de maiores taxas de crescimento econômico.

Em síntese, Flingespan (2009, p.60) afirma que:

“... Também conhecida como "Lei de Thirlwall”, ela tem como referência um contexto de restrições ao financiamento do Balanço de Pagamentos,

\footnotetext{
Thirlwall assevera, contudo, que tais restrições físicas de oferta podem se tornar operacionais quando e onde houver uma combinação de cenário internacional favorável com estruturas produtivas mais sofisticadas e políticas adequadas de gestão da demanda agregada.

6 Na prática, é conveniente tratar z como uma média das taxas de crescimento dos principais destinos das exportações de cada país, ponderadas pelas respectivas participações desses destinos nas exportações totais do país. Portanto, z tampouco é estritamente independente da política econômica nacional, posto que essas participações podem variar em função do perfil de política externa. O retorno do Itamaraty a uma política externa "terceiro-mundista" a partir de 2002, por exemplo, provavelmente contribuiu para elevar $\mathrm{z}$ durante a primeira década do milênio, quando os países do terceiro mundo via de regra cresceram mais depressa do que os desenvolvidos.
} 
em que as exportações têm que crescer para gerar as divisas necessárias ao pagamento das importações. Estas, por sua vez, não podem se expandir muito em relação à renda, sob pena de gerar déficits crescentes e não financiáveis. Trata-se, portanto, da busca de uma combinação adequada entre crescimento, exportações e importações de modo que as contas externas não representem uma restrição ao crescimento do PIB".

Cumpre frisar que os países que exportam produtos de baixa elasticidaderenda, e importam produtos de alta elasticidade-renda, necessariamente crescerão menos do que a média da economia mundial. Dessa maneira, caso essa estrutura produtiva não seja modificada, haveria uma tendência para que a distância entre as economias desenvolvidas e em desenvolvimento aumente cada vez mais. Nesta análise, o conteúdo das exportações é relevante e sua elasticidade-renda (determinada pela estrutura produtiva de cada país) pode restringir a obtenção de maiores taxas de crescimento econômico.

Os efeitos de longo prazo da continuidade de tal performance fornecem a explicação de Thirlwall para a chamada tendência à polarização. É necessário esclarecer, contudo, que períodos nos quais os países mais atrasados cresçam mais velozmente do que os adiantados (como parece ter sido o caso na primeira década do milênio) não invalidam necessariamente o modelo. Isto porque:

1) O modelo se pretende válido apenas em certo "longo prazo", o qual não é teoricamente especificado; em tese, uma década pode não ser tempo suficiente para que a restrição em questão se manifeste; especialmente quando os fluxos de capitais são abundantes, e os termos de troca particularmente favoráveis;

2) Certos países, talvez particularmente os já desenvolvidos, podem não desejar expandir a demanda agregada na intensidade permitida pela sua restrição de balanço de pagamentos. Neste caso, a despeito da tendência à polarização continuar presente em função dos aspectos estruturais, pode se manifestar empiricamente um processo de convergência;

3) O modelo prevê que a polarização só se manifesta caso os países subdesenvolvidos não vierem a utilizar políticas de mudança estrutural na escala necessária; na prática, os dados empíricos captam o efeito combinado da operação das forças de mercado e dessas políticas governamentais, impedindo que o tratamento meramente descritivo dos dados empíricos tenha peso decisivo para a rejeição do modelo?.

7 Repare que a validade da hipótese de polarização é empiricamente mais exigente do que a da mera validade do modelo de Thirlwall. Para que a hipótese de polarização seja válida, é preciso que a configuração das elasticidades-renda de exportação e importação dos países subdesenvolvidos seja adequada. Já a validade do modelo exige apenas que a taxa de crescimento efetiva do produto não permaneça indefinidamente acima de $\mathrm{g}_{\mathrm{BP}}$. 
Tal qual o modelo de Thirlwall, a abordagem de Kaldor (1970) sobre a teoria do crescimento econômico considera que este também é liderado pela demanda e restringido pelo balanço de pagamentos. Entretanto, o foco de sua análise tem um caráter mais especificamente setorial.

Kaldor estabelece que a taxa de crescimento das exportações determina o crescimento do PIB real, dado o parâmetro ${ }^{8}$ que mede a elasticidade desta relação. Assim, um crescimento mais rápido das exportações proporciona uma maior taxa de crescimento da economia, mediante mecanismo similar ao multiplicador de comércio externo (HARROD, 1939) 9

O passo seguinte do argumento, baseado na Lei de Verdoorn, postula que o aumento na taxa de crescimento da economia eleva a taxa de crescimento da produtividade em geral, da industrial em particular. A produtividade é portanto endógena e depende parcialmente do progresso técnico autônomo e, em boa medida, do induzido. A economia que apresenta maior produtividade se apropria dos ganhos dinâmicos de escala, sendo esta a variável-chave do modelo na explicação das diferentes taxas de crescimento entre os países (tendência à polarização $)^{10}$. Partindo deste princípio, Kaldor observa o setor industrial como o (então) mais dinâmico e o responsável pelo progresso técnico. Para ele parece acertado que neste setor as inovações ocorrem mais rapidamente e os ganhos de produtividade contribuem para o crescimento econômico (FEIJÓ; CARVALHO, 2002) $)^{11}$.

\footnotetext{
Tal parâmetro está relacionado ao comportamento das importações. Quanto maior o setor de produção de bens de capital do país, menor é a elasticidade renda de suas importações, o que por sua vez permite uma taxa de crescimento compatível com o equilíbrio do balanço de pagamentos mais elevada (FREITAS, 2002, 2003).

9 Cabe ainda ressaltar que as exportações podem exercer a liderança do crescimento também como componente de expansão da demanda autônoma, desencadeando, além dos tradicionais efeitos multiplicadores, também efeitos sobre o investimento similares aos do modelo do acelerador proposto por Hicks (1950).

10 Note que, subjacente a estas leis, podemos verificar a presença do "princípio da causação circular e cumulativa" proposto por Myrdal (1957). Dessa maneira, um país que cresce mais rapidamente acaba colhendo os frutos na forma de crescimento acelerado da produtividade industrial, sendo esta repassada e absorvida por outros setores da economia. Caso um país não desfrute inicialmente de tal crescimento, poderá apresentar taxas de crescimento cada vez mais baixas (de forma cumulativa), sendo que, no longo prazo, as divergências de suas taxas de crescimento em relação às demais economias podem aumentar de forma contínua.

11 No que tange às contribuições para a análise das divergências entre as taxas de crescimento das economias, Kaldor apresenta três leis fundamentais ("leis de Kaldor"): 1) a indústria de transformação se apresenta como motor do crescimento de longo prazo das economias, sendo que 2) o próprio crescimento econômico induz ao aumento da produtividade industrial através dos retornos dinâmicos de escala, e 3) o crescimento da produção induz o crescimento da produtividade fora do setor industrial, absorvendo recursos de baixa produtividade de outros setores (THIRLWALL, 1996).
} 
A aceleração do crescimento da produtividade possibilita uma queda na inflação interna, e como a PPC não é considerada válida ${ }^{12}$, a taxa real de câmbio sofre desvalorização. Como a condição de Marshall-Lerner é supostamente obedecida no prazo do modelo, a taxa de crescimento das exportações responde positivamente, dando origem a um novo movimento cumulativo da taxa de crescimento do PIB e da produtividade (causação cumulativa). Em síntese, as exportações desempenham um papel essencial nos dois modelos acima expostos, por ser o único componente da demanda agregada capaz de crescer sem sofrer limites devidos à restrição externa. Pelo contrário, permitem a ampliação da taxa de crescimento compatível com a restrição do balanço de pagamentos, dependendo de seu conteúdo tecnológico ${ }^{13}$.

Pode-se questionar até que ponto - como fazem aliás Dasgupta e Singh (2006) - a indústria continua tão estratégica quanto ao tempo de Kaldor. Mesmo admitindo que alguns serviços sofisticados tenham assumido a liderança, por exemplo, pelo critério da elasticidade-renda, a conclusão desses autores é que ela continua relativamente importante. O ponto, contudo, é que importa para o modelo é o grau de sofisticação da pauta de exportação e da composição do produto, e não propriamente o setor que assume o posto que então era da indústria.

Neste sentido, o conteúdo tecnológico das exportações e das importações nas economias em desenvolvimento torna-se relevante, na medida em que permite tal folga externa, reduzindo ademais a dependência que estas economias possuem de um cenário externo particularmente favorável.

Logo, assim interpretado este referencial teórico parece útil ao entendimento da situação atual do Brasil em relação às demais economias em desenvolvimento, principalmente os demais BRIC.

\section{ESTRUTURA PRODUTIVAE DESEMPENHO DAS EXPORTAÇÕES DOS BRIC (1980-2012)}

No decorrer dos últimos 30 anos, o valor adicionado dos setores produtivos da economia no PIB dos BRIC passou por modificações relevantes. Conforme demonstra o Gráfico 2, ao analisarmos a composição do PIB por setor, a economia brasileira atravessou substanciais modificações em sua estrutura produtiva. Entre

12 Portanto, diferentemente do modelo proposto por Thirlwall, em Kaldor as desvalorizações do câmbio afetam positivamente a taxa de crescimento das exportações e, por consequência, a taxa de crescimento do produto real de longo prazo.

13 Repare contudo um detalhe específico do modelo de Kaldor: o círculo virtuoso cumulativo pode ter por "gatilho" a expansão de uma variável autônoma de demanda doméstica, desde que as condições iniciais do balanço de pagamentos o permitam. Os ganhos dinâmicos de escala daí resultantes poderiam perfeitamente espraiar-se aos setores industriais exportadores, colocando então em marcha um processo de crescimento mais sustentável. 
as décadas de 1980 e 2010, a agricultura reduziu sua participação pela metade (de $11 \%$ para 5,7\%, em média), acompanhada pela indústria (de $43 \%$ para $27 \%$ ). No entanto, a do setor de serviços elevou-se 20 pontos percentuais (p.p.) no mesmo período (passando de 45\% para 66\% do valor adicionado ao PIB).

Gráfico 2 - Valor adicionado por setor (\% do PIB); BRIC; 1980-2012

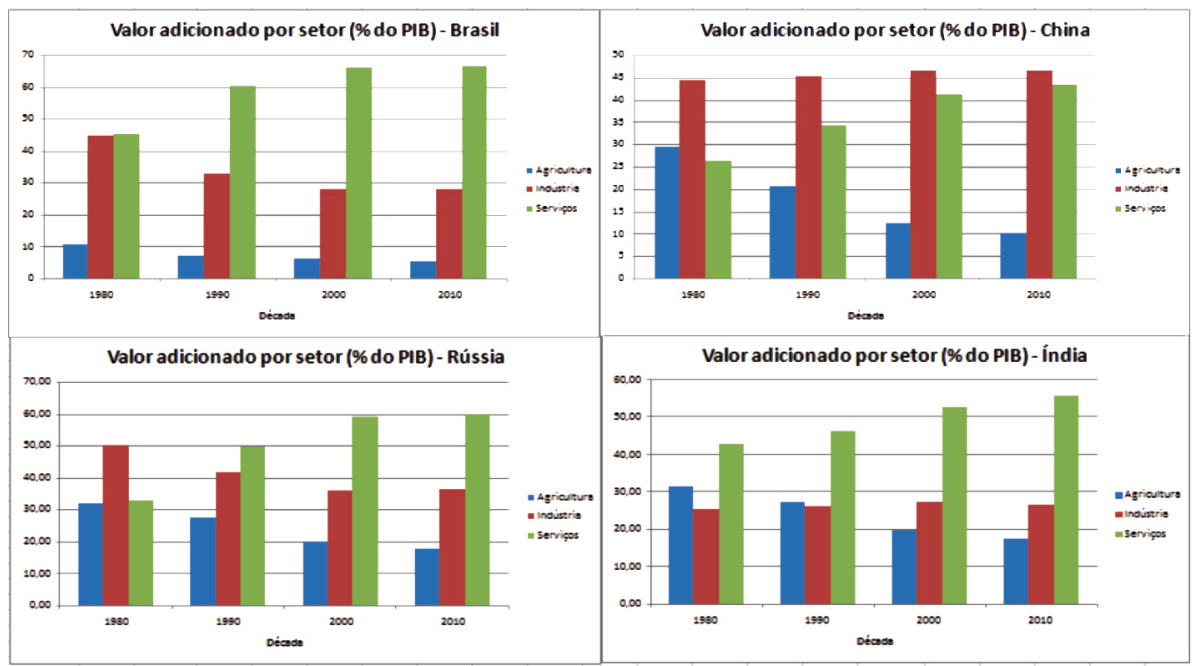

Fonte: World Development Indicators Database (2013).

A China apresenta uma trajetória bastante distinta das demais economias que compõem o grupo. Desde as reformas de Deng Xiaoping em 1978 ${ }^{14}$, a economia chinesa vivenciou um significativo processo de industrialização, com pesados investimentos estatais em setores específicos, especialmente aqueles relacionados com as exportações, como a criação das Zonas Econômicas Especiais (ZEE). Deste modo, na década atual, a participação do setor agrícola foi reduzida para aproximadamente um terço da verificada na década 1980, reduzindo sua participação de 29\% para aproximadamente 10\% no início de 2010, dando lugar à indústria, que saiu de $42 \%$ para $52 \%$ do PIB. O setor de serviços também elevou sua participação, passando de $26 \%$ para $43 \%$, considerando o mesmo período.

$\mathrm{Na}$ Índia, a agricultura e os serviços participavam em aproximadamente $31 \%$ e $42 \%$ do PIB, na década de 1980, respectivamente. No entanto, no decorrer de 30 anos, passaram a apresentar trajetórias significativamente distintas. No caso da agricultura, sua participação foi reduzida para 17\%. Já os serviços saltaram para aproximadamente $55 \%$ no início da década. A indústria, por sua vez, manteve uma participação próxima dos $26 \%$ em todo o período.

14 Não é objetivo deste trabalho examinar as reformas vivenciadas pela China a partir de $1978 \mathrm{e}$ sua performance de crescimento. Acerca desse aspecto, vide Medeiros (1999, 2008, 2010). 
Finalmente, a Rússia quase dobrou a participação do setor de serviços no PIB, saindo de 32\% nos anos de 1980 para aproximadamente 60\% na presente década. Tanto a indústria como a agricultura reduziram suas participações (que eram 50\% e 16\%, nos anos 80, para 36\% e 4,1\%, na década de 2010, respectivamente). Atualmente, a Rússia apresenta pesados investimentos em tecnologias relacionadas a produtos militares e energia (MEDEIROS, 2008).

O Gráfico 2 nos permite obter algumas conclusões: a) apenas no caso da economia chinesa a participação do setor de serviços é menor do que a dos demais setores; b) em todos os países que compõem o BRIC a agricultura apresenta a menor participação atualmente; c) O Brasil e a Rússia têm apresentado uma trajetória de perda na participação relativa da indústria no PIB, no entanto no Brasil tal participação é ainda menor ${ }^{15}$.

Gráfico 3 - Valor adicionado da Indústria de transformação (\% do PIB); BRIC, 1980-2012.

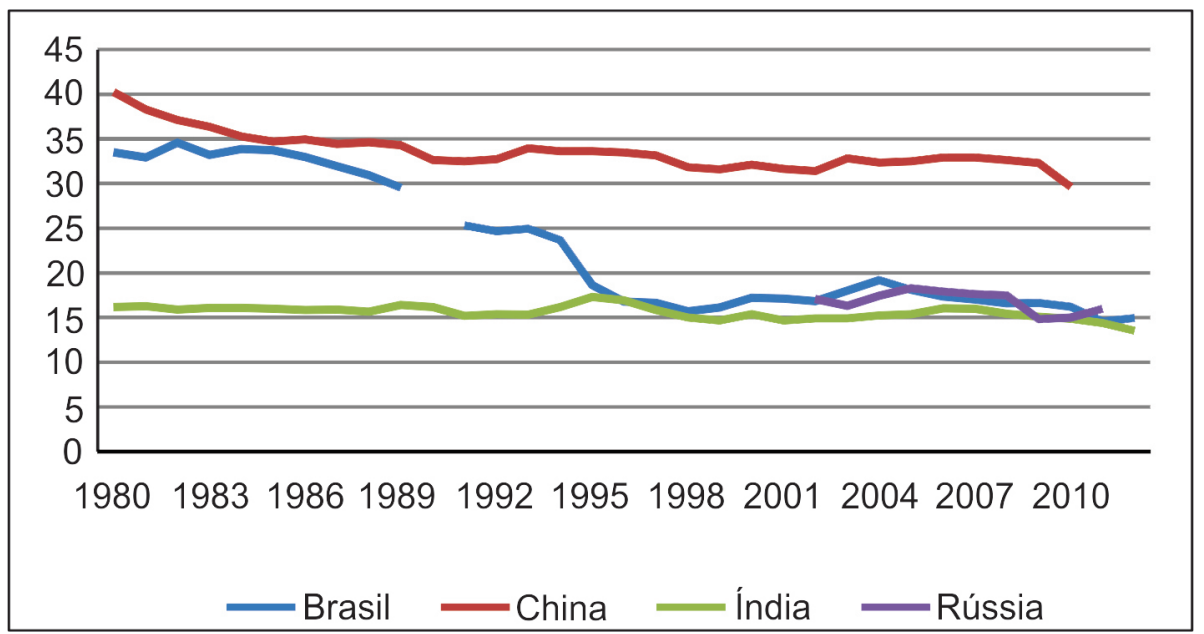

Fonte: World Development Indicators Database (2013).

Face ao exposto, o valor adicionado da indústria no PIB teve um comportamento assimétrico entre os BRIC. Observando especificamente o desempenho da indústria de transformação no Gráfico 3, desde a década de 1980 o Brasil apresenta queda persistente neste segmento. Atualmente esta indústria representa a metade da participação no início dos anos 80. Neste contexto, o Brasil sai de um patamar elevado, próximo ao chinês, igualando-se aos demais BRIC, com participação em torno de $15 \%$.

15 Entretanto, vale lembrar que na Rússia a indústria extrativa é muito importante, e deve ser desmembrada da indústria de transformação para que se tenha uma análise mais adequada do atual estágio da última. 
Não obstante, em se tratando da China, mesmo caindo 10 pontos percentuais, a indústria de transformação continua tendo elevada participação no PIB (aproximadamente 30\%). Já os dados disponíveis a partir de 2003 para a Rússia mostram uma trajetória constante desta variável, fato que também pode ser observado no caso da economia indiana.

A análise acima mostra que atualmente a economia que tem ampliado mais rapidamente a indústria de transformação é a chinesa, e a performance do seu PIB é consistente com o argumento de Kaldor. No mesmo sentido, a queda da participação da indústria de transformação no Brasil parece guardar relação com a queda da taxa de crescimento do produto.

O argumento de Kaldor não é, contudo, a única explicação possível para o fenômeno, posto que a existência de correlação entre ambas as variáveis não implica necessariamente a causalidade por ele postulada. É possível, alternativamente, que a queda na taxa de crescimento do produto - provocada por algum outro fenômeno - tenha, via efeito acelerador, reduzido a participação do investimento no PIB brasileiro. Como apontado pelo próprio Kaldor, o investimento é essencialmente industrial. Por essa via, portanto, seria possível apontar a existência de uma causalidade reversa. Fenômeno simétrico poderia ser invocado para explicar o caso chinês.

A análise de suas respectivas taxas de formação bruta de capital fixo ${ }^{16}$ (FBCF) em percentual do PIB nos ajuda a entender o comportamento da indústria de transformação. Atualmente, a FBCF representa 45\% do PIB chinês, a participação mais elevada entre os BRIC (Gráfico 4).

Gráfico 4 - Formação Bruta de Capital Fixo (\% do PIB); BRIC, 1980-2012

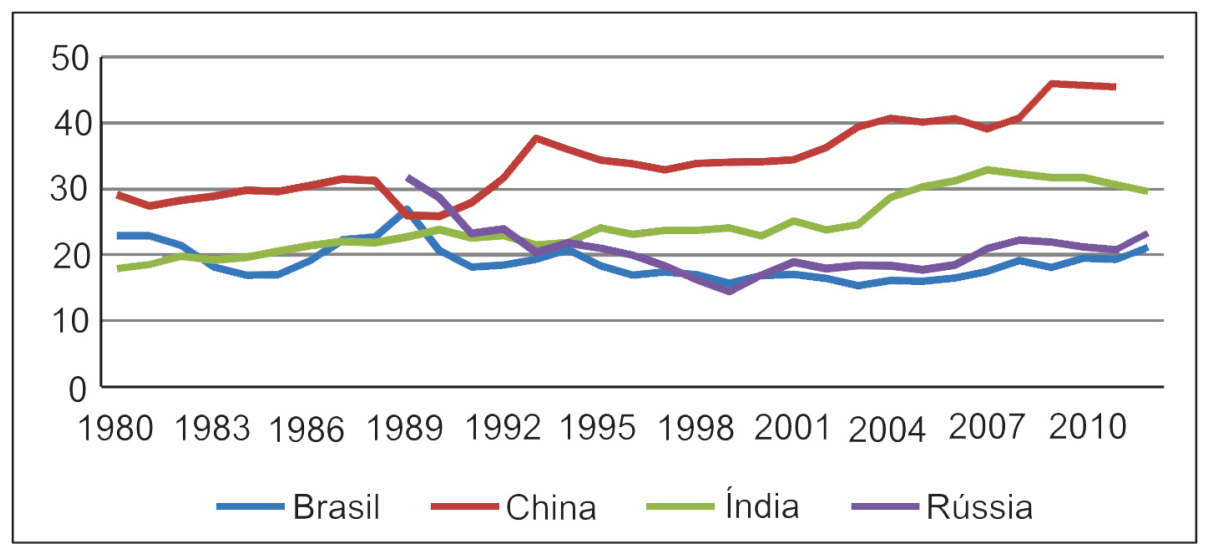

Fonte: World Development Indicators Database (2013).

$\overline{16}$ Considerada como proxy da taxa de investimento. 
No que concerne à Índia, a FBCF ocupa atualmente a segunda maior participação entre os países emergentes selecionados. Este indicador quase dobrou, saindo de 17\% em 1980 para algo em torno de 32\% em 2012.

A partir de 2000 a FBCF do Brasil é a menor do grupo, em torno de 20\% em média. O desempenho desta variável na Rússia apresentou trajetória decrescente ao longo do tempo, com sinais de recuperação a partir de 2001, chegando atualmente aos $22 \%$ do PIB.

Os dados do Brasil e da China são consistentes com ambas as explicações anteriormente aventadas para o co-movimento da participação no PIB da indústria de transformação e do crescimento do produto. Os casos da Índia e da Rússia parecem de mais difícil interpretação, na medida em que a elevação da taxa de investimento em ambas não é acompanhada por um aumento da participação da indústria de transformação.

No que tange à importância adquirida pelo BRIC no cenário internacional, Bamann, Araújo e Ferreira (2010) revelam que a participação das exportações chinesas no comércio mundial merece destaque, na medida em que aumentou aproximadamente cinco vezes na última década (passaram de 1,6\% em 1990 para 7,7\% em 2008).

Não obstante, nos demais países pertencentes ao grupo esta participação pouco se alterou. No caso brasileiro, a participação aumentou em 0,1 p.p. (passando de 0,9\% em 1990 para 1\% em 2008). A Rússia apresentou tendência semelhante à brasileira, elevando sua participação em 0,2 p.p. no mesmo período (de 2,1\% para 2,3\%). Já a Índia aumentou em três vezes sua participação (de 0,5\% em 1990 para 1,4\% em 2008), entretanto continua com uma participação pouco significativa.

Esse indicador de participação das exportações na corrente de comércio mundial nos fornece uma primeira indicação, ainda grosseira, das elasticidadesrenda envolvidas. China e Índia parecem dispor de elasticidades significativamente superiores a um, o oposto se dando com Rússia e Brasil, onde parecem próximas da unidade. Como visto no modelo de Thirlwall, isto tende a dotar as economias chinesa e indiana de uma taxa de crescimento sustentável mais elevada, e a gerar o fenômeno oposto sobre as economias russa e brasileira. E, seguindo Kaldor, esse fenômeno tende a prejudicar o crescimento da produtividade (tanto industrial quanto geral) nestas últimas duas nações vis-à-vis as primeiras, alterando a competitividade relativa das suas exportações e, portanto, reforçando o comportamento heterogêneo do crescimento. 
Tabela 1 - Participação das exportações de bens e serviços (\% do PIB) BRIC, 1970-2012.

\begin{tabular}{c|c|c|c|c|c}
\hline & Década 1970 & Década 1980 & Década 1990 & Década 2000 & Década 2010 \\
\hline Brasil & 7,5 & 10,1 & 8,5 & 13,4 & 11,9 \\
\hline China & 4,7 & 13,0 & 21,6 & 34,3 & 31 \\
\hline Índia & 5,3 & 6,0 & 10,0 & 17,6 & 23,2 \\
\hline Rússia & n.d. & n.d. & 31,4 & 34,3 & 29,6 \\
\hline
\end{tabular}

Fonte: World Development Indicators Database (2013).

n.d.: não disponível.

Os dados da Tabela 1 mostram a participação das exportações de bens e serviços no PIB de cada país, no período 1970-2012. No caso do Brasil, a participação das exportações quase dobrou nos anos 2000, entretanto sua taxa é a mais baixa dentre os países considerados, e representa aproximadamente um terço das participações da Rússia e da China, e a metade da indiana no período recente.

A Rússia e a China são os países que apresentam participações mais elevadas em relação ao grupo, no entanto no caso da Rússia, os dados para as décadas de 1970 e 1980 não se encontram disponíveis para comparações. Observando o caso chinês, verifica-se que a participação das exportações no PIB elevou-se 6,6 vezes. No que se refere à Índia, a participação aumentou em 4,4 vezes, entretanto é a segunda economia com participação mais baixa (à frente apenas do Brasil) dentre os BRIC.

A participação das importações chinesas e indianas no comércio mundial seguiu trajetória semelhante às exportações: a China aumentou sua participação em aproximadamente 5 vezes (passou de 1,3\% em 1990 para 6,0\% em 2008) e a Índia elevou sua participação 3 vezes (de 0,6\% em 1990 para 1,7\% em 2008). O Brasil ampliou sua participação em 1,2 vezes, no entanto representa menos de 1\% do comércio mundial (passando de 0,7\% em 1990 para 0,9\% em 2008). Das economias analisadas a Rússia foi a única cuja participação foi reduzida (de 2,1\% em 1990 para 1,6\% em 2008).

Os dados sobre importações e exportações de bens e serviços como \% do PIB, bem como os dados sobre o PIB mundial disponíveis na base de dados do Banco Mundial podem ser utilizados portanto para estimar a elasticidade-renda média das exportações e das importações para o período 1989-2013, bem como para subperíodos selecionados. Os dados são apresentados na Tabela 2 abaixo: 
Tabela 2 - Estimativas para a elasticidade-renda das exportações $(\boldsymbol{\varepsilon})$, a elasticidaderenda das importações $(\boldsymbol{\pi})$ e a razão entre elas $(\boldsymbol{\varepsilon} / \boldsymbol{\pi})$; BRIC, 1989-2013

\begin{tabular}{c|c|c|c|c}
\hline & Brasil & China & Índia & Rússia \\
\hline$\varepsilon$ & 1,54 & 3,38 & 2,44 & 1,28 \\
\hline$\pi$ & 1,64 & 1,24 & 1,74 & 1,05 \\
\hline$\varepsilon / \pi$ & 0,93 & 2,74 & 1,41 & 1,22 \\
\hline
\end{tabular}

Fonte: World Development Indicators Database (2013), elaboração própria.

Os dados permitem delinear uma hierarquia interessante em termos de potencial de crescimento sustentável: a China pode crescer 2,74 vezes mais depressa que o PIB mundial (ou o dos principais parceiros) a cada ano sem enfrentar restrições de balanço de pagamentos; a Índia, 1,41 vezes; a Rússia, 1,22 vezes; e o Brasil, 0,93 vezes. Isso significa que o comportamento estrutural das exportações e das importações do Brasil é fator fundamental para explicar o desempenho do tipo falling behind que este país vem enfrentando desde a "crise da dívida" dos anos 80: uma razão entre as elasticidades inferior a um simplesmente impossibilitou a aceleração sustentável do crescimento.

Note-se também que essa hierarquia é extremamente sugestiva, pois a ordem de crescimento dos PIBs efetivos só discrepa desta pela inversão de posições entre Brasil e Rússia. Também é interessante observar que, se desconsiderado o caótico início dos 90 neste último país, a hierarquia se mantém estritamente.

O Gráfico 5 permite avaliar a evolução deste indicador, crucial para o desempenho relativo dos países, ao longo de três subperíodos.

Gráfico 5 - Evolução do indicador $\varepsilon / \pi$ em subperíodos selecionados; BRIC, 1989-2013.

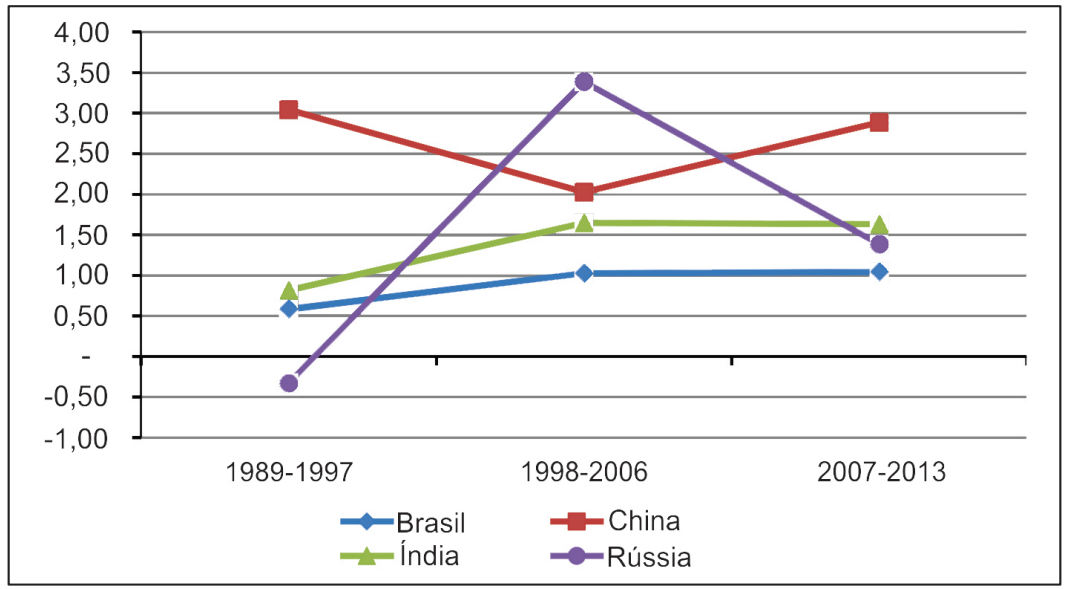

Fonte: World Development Indicators Database (2013).

Novos Cadernos NAEA • v. 21 n. 1 • p. 9-33 • jan-abr 2018 
Em primeiro lugar ressalta-se a volatilidade do indicador russo, posto que o período de crise do desmanche da antiga URSS influencia os dados iniciais (afora a conhecida sensibilidade russa ao movimento dos preços das commodities, claramente expresso pela inflexão causada pela crise recente). Em segundo lugar, chama a atenção o fato de que os demais membros mantêm suas posições relativas ao longo dos três subperíodos. Mostra-se ainda o indicador brasileiro profundamente afetado pelo "desastre" dos anos 90, superando marginalmente o valor crítico um desde então. É interessante também observar que o indicador brasileiro não infletiu desde a eclosão da crise em 2007/2008, o que significa que a desaceleração recente do crescimento não foi causada por uma adicional perda relativa de competitividade.

Passamos agora a tentar entender melhor os componentes estruturais que determinaram este comportamento das exportações. Com base no Gráfico 6, no período entre 1988 e 2009, percebe-se que as exportações de alta tecnologia como percentual das exportações de manufaturas cresceram de forma acelerada na China (passando de 6\% em 1992, para 31\% em 2009). A Índia foi a economia que apresentou participação mais baixa (9\%), assim como a Rússia (9\%), entretanto a primeira seguiu uma trajetória constante, enquanto a segunda vivenciou muitas oscilações durante o período em análise. No caso do Brasil, as exportações de produtos de alta tecnologia representaram 14\% das exportações de manufaturados atualmente, no entanto, chegou a atingir um pico de $19 \%$ do total das exportações em 2000. A Rússia apresentou um pico em 2002 (20\%), seguido contudo por brusca queda a seu ponto de partida nos anos 1990.

Gráfico 6 - Exportações de alta tecnologia (em \% das exportações de manufaturas); BRIC, 1988-2009.

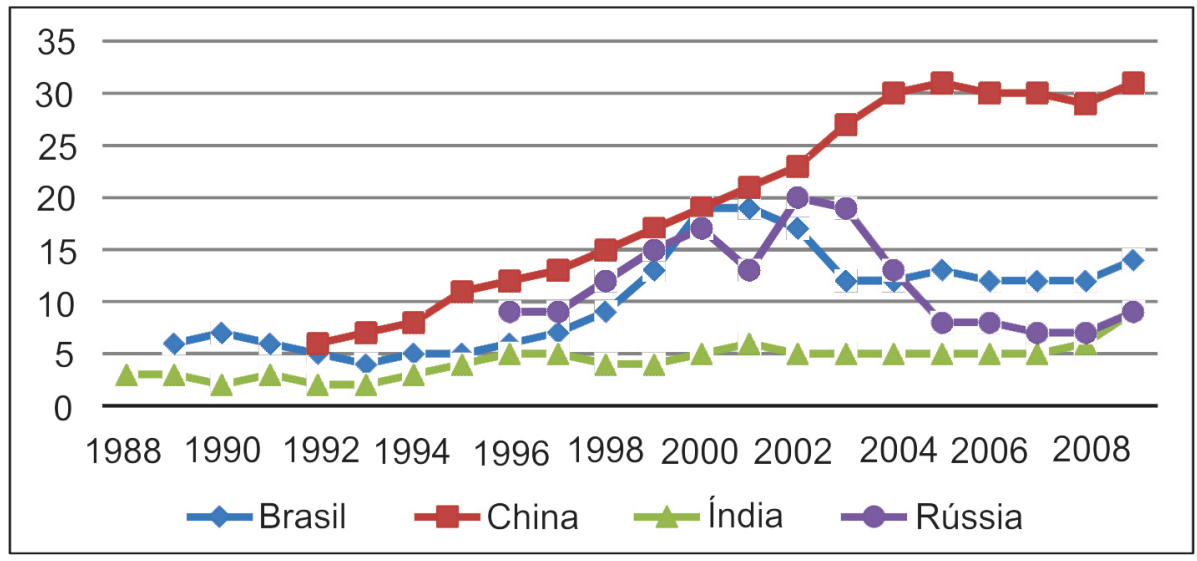

Fonte: World Development Indicators Database (2013). 
Como o foco desta análise é a economia brasileira, pode-se afirmar que fica patente que o padrão de especialização brasileiro não é constituído por produtos de alta tecnologia, onde o minério de ferro, soja e petróleo correspondem a 70\% da pauta exportadora do Brasil (IBGE, 2011). Desta forma, as exportações são intensivas em recursos naturais e commodities, diferentemente da pauta exportadora da China, intensiva em manufaturas e tecnologia da informação.

Gráfico 7 - Exportações e Importações de manufaturas (\% das exportações e importações totais); BRIC, 1980-2012.

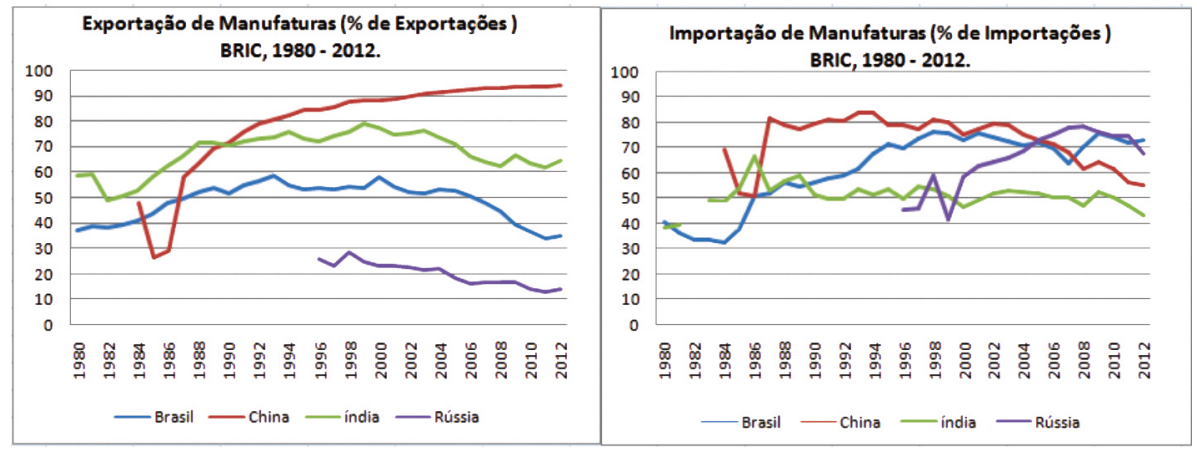

Fonte: World Development Indicators Database (2013).

A China se destaca na medida em que, desde 2000, os termos de troca foram desfavoráveis às suas exportações, o que, entretanto, não a impediu de atingir o status de maior exportadora mundial. Tal performance se deve às elevadas elasticidades renda de suas exportações, conforme ela foi promovendo políticas econômicas voltadas à gradual elevação da sofisticação de sua estrutura produtiva, cujos impactos são visíveis no Gráfico 8. Em contrapartida, o coeficiente de importação chinês é elevado, pois a mesma importa do Japão e de outros países asiáticos produtos fragmentados da cadeia produtiva na área de tecnologia de informação, ficando responsável pela montagem e reprocessamento das exportações (MEDEIROS, 2010).

Atualmente, a China é a maior exportadora do mundo e ocupa a posição de segunda maior importadora mundial, entretanto ela não é a maior produtora. Isto desperta atenção, pois a parcela das exportações chinesas no produto mundial é superior a parcela da produção industrial chinesa no produto mundial (MEDEIROS, 2010).

No tocante à Rússia, o padrão de especialização é voltado para as exportações de commodities (principalmente energéticas), e a elevação nos preços destas na década de 2000 tem contribuído para a significativa expansão econômica vivenciada no período recente. Assim, mesmo após enfrentar uma 
grave depressão na década de 1990, decorrente do esfacelamento da URSS, a partir de 1999, o aumento dos preços do petróleo e uma conjuntura internacional favorável contribuíram para recuperação nas taxas de crescimento do PIB e para o aumento das exportações (CARVALHO, 2009).

A Índia apresentou significativas mudanças na composição de suas exportações desde o início das reformas em 1991. De acordo com Leão e Oliveira (2010), as transformações nesta composição podem ser divididas em duas fases: na primeira, a composição das exportações de todos os tipos de produtos ficou constante (1995 a 2002); entretanto, na segunda fase, os setores básicos e outros manufaturados continuaram liderando as exportações, porém os setores de combustível e máquinas e equipamentos foram os que mais cresceram.

Para se ter uma ideia do estado do Brasil em relação aos demais países que compõem o BRIC, no que tange aos investimentos em Pesquisa e Desenvolvimento $(\mathrm{P} \& \mathrm{D})$, pode-se observar os dados acerca dos respectivos sistemas nacionais de inovação, conforme exposto por Lastres et al (2007, p.16).

A Rússia apresenta forte posição relativa no que concerne ao investimento em educação superior, com poderoso sistema científico, particularmente dedicado às atividades espaciais e relacionadas à defesa, além de apresentar expansão nos gastos em P\&D.

Já a Índia tem se destacado pela alta qualidade do sistema científico (e em expansão), entretanto com P\&D industrial relativamente modesta. Os recursos humanos presentes são de alta qualidade e capacitações produtivas particularmente em tecnologias da informação.

Observando a China, verifica-se um acúmulo de capacitações produtivas e inovativas com esforço em atividades de P\&D crescendo a taxas elevadas, com ênfase nos setores bi-tech.

No Brasil, o sistema científico tem se qualificado. No entanto, as atividades de P\&D são bastante desiguais, com sucessos em áreas específicas (aeroespacial, energia, mineração, metalurgia e agronegócios). A partir da década de 1990 houve uma fragilização e desarticulação de alguns sistemas de inovação.

Ainda segundo Lastres et all (2007, p.17), os principais problemas encontrados no sistema de inovação brasileiro são:

“a'fraca' performance competitiva com significativas fragilidades na produção e na exportação em setores de alto valor agregado e alto conteúdo tecnológico; mudanças patrimoniais significativas em diversos setores, com perda de participação de capital nacional; vulnerabilidade financeira dos grupos de capital nacional, resultado do alto custo do capital e inexistência ou ineficácia de mecanismos de financiamento de longo prazo". 
Fica sugerido pela experiência chinesa o aproveitamento das oportunidades ${ }^{17}$ e a utilização da folga externa para a promoção de modificações relevantes na estrutura produtiva de sua economia. Isto permitiu a intensificação das exportações de bens com maior conteúdo tecnológico ${ }^{18}$.

Deste modo, a economia chinesa, além de aproveitar as oportunidades surgidas pela conjuntura internacional, contou (e ainda conta) com instituições internas, e principalmente, com muitas das políticas (senão todas) fundamentais ao desenvolvimento esboçadas por OCAMPO, JOMO e VOS (2007): política macroeconômica de suporte (sobretudo cambial), proteção seletiva a indústria nascente, subsídios às exportações, direcionamento do crédito, alianças estratégicas com multinacionais e investimento em recursos humanos.

No caso da China, por exemplo, os vários planos quinquenais foram estratégicos e modificaram a estrutura produtiva chinesa, podendo-se citar como principais políticas: a criação das ZEEs; a taxa de câmbio significativamente desvalorizada; pesados investimentos em recursos humanos; acordos bilaterais (principalmente com o Japão) e com multinacionais, entre outros. Assim, os planos quinquenais responderam, e ainda respondem, às necessidades nascentes da indústria nacional em cada período (MEDEROS, 2008).

No caso do Brasil não existe um projeto explícito de desenvolvimento econômico, como verificado na China, nem tampouco uma maior integração entre as cadeias produtivas industriais. Mesmo com os sinais de recuperação do desempenho exportador desde 2002, esta melhora parece ter refletido principalmente o ambiente externo benigno (PRATES, 2005) decorrente do crescimento da China ${ }^{19}$ e dos Estados Unidos, bem como da melhora nos termos de troca para os principais produtos de exportação da pauta brasileira.

Seria precoce, e até mesmo exagerado, afirmar que a Índia alcançará os patamares da China em termos de conteúdo tecnológico das exportações no curto prazo. Entretanto, a FBCF (em \% do PIB) da Índia é a segunda mais alta (em torno de $30 \%$ ) entre os países que compõem os BRIC. Como visto, isto tende a acelerar a velocidade de difusão do progresso técnico incorporado nos bens de capital e o crescimento da produtividade nos diversos setores da sua economia.

\footnotetext{
17 Podendo-se citar o desenvolvimento a convite feito pelos Estados Unidos à China e a Índia.

18 Outro caso de relativo sucesso que pode ser citado é a Coréia do Sul, entretanto não é objeto deste estudo. Uma análise sobre as transformações na estrutura produtiva na Coréia do Sul, bem como as principais políticas que propiciaram tais transformações pode ser encontrada em Coutinho (1999) e Canuto (1994).

19 Decorrente da elevação na demanda chinesa por commodities.
} 


\section{CONSIDERAÇÕES FINAIS}

Mesmo apresentando taxas de crescimento do produto relativamente elevadas na última década, o comportamento das exportações, bem como o seu conteúdo, tem se manifestado de forma distinta em cada um dos BRIC. A comparação entre eles revelou uma série de fenômenos e regularidades empíricas no período analisado que convém resumir:

As taxas de crescimento relativas das economias estiveram estreitamente associadas às respectivas razões entre as elasticidades-renda da demanda por exportações e por importações, como sugere a análise de Thirlwall; a análise porém precisa ser matizada conforme o subperíodo, o que sugere que a extensão dos subperíodos adotados (entre 6 e 8 anos) é insuficiente para que os fatores estruturais da análise teórica se manifestem integralmente;

Os países que cresceram mais rapidamente são os que menos perderam participação tanto do setor industrial em geral quanto especificamente da indústria de transformação no valor agregado, como sugere o tratamento de Kaldor;

Os países que crescem mais depressa apresentaram taxas de investimento mais elevadas (o que pode inclusive ajudar a explicar o fato anterior), também em consonância ao arcabouço empírico tratado no artigo;

Esta "associação de hierarquias" não se mantém completamente quando se observam os indicadores \% das exportações e importações industriais nas exportações e importações totais; e \% das exportações de alta tecnologia nas exportações industriais. Embora de fato a China e a Índia se mantenham como líderes no primeiro indicador, Brasil e Rússia invertem posições, possivelmente devido à enorme concentração das exportações russas em commodities (e todos, exceto a China, perdem participação industrial nas exportações totais). E a despeito da China também permanecer como líder no segundo indicador, o Brasil supera Índia e Rússia (hoje virtualmente empatados). A posição brasileira neste aspecto talvez ajude a explicar porque as elasticidades-renda das exportações e importações se recuperaram ligeiramente dos números desastrosos da década de 1990, sem tampouco gerar situação externa confortável.

Diante desse quadro, a hipótese do trabalho não parece falsificada, embora algumas qualificações precisem ser adotadas.

Os dados revelam que a China tem continuado seu processo de transformação estrutural, mudando o foco das políticas conforme as necessidades dos setores mais sofisticados. Neste sentido, parecem validar (ao menos entre o grupo analisado) o bordão de Myrdal (1957, p. 21), segundo o qual “em geral, são 
os países industrializados os que estão se industrializando mais", e a busca pela inovação neste setor é crescente.

A Rússia tem se recuperado após a terrível crise econômica e mesmo humanitária da década de 1990. Contudo, ela enfrenta hoje sérios problemas estruturais em decorrência de sua dificuldade de empregar civilmente a tecnologia militar que continua a desenvolver, e da elevada sensibilidade da economia às oscilações nos preços das commodities, em particular das energéticas. A escassez de dados comparáveis no período socialista impediu uma análise mais profunda desta economia.

Já a Índia tem crescido de forma relativamente regular ao longo do período analisado e é vista como uma economia bastante promissora para os próximos anos. Sua frágil agricultura, porém, continua sendo seu calcanhar de Aquiles (NAGARAJ, 2008), e sua questão energética continua em aberto, a despeito do recente acordo nuclear com os EUA. Avanços recentes na \% das exportações de alta tecnologia nas exportações industriais parecem apontar um possível canal de aprofundamento do desenvolvimento.

Pode-se concluir que, em termos de estrutura, a economia indiana não se encontra em estágio muito distinto do brasileiro, na medida em que os dados revelam performances semelhantes. Na Índia a participação do valor adicionado da indústria no PIB é $26 \%$, enquanto no Brasil esta participação é de $27 \%$. No que concerne às exportações de produtos de alta tecnologia em percentual das exportações de manufaturas, o Brasil apresenta resultado superior ao indiano, 14\% a 9\%. Entretanto, enquanto as exportações de manufaturas em percentual das exportações totais apresentam trajetória crescente na Índia (média de 70\% entre 2000 e 2012), no Brasil esta trajetória é decrescente (média de 47\% entre 2000 e 2012), principalmente a partir de 2009, quando passou a representar $37 \%$ das exportações totais.

A principal mensagem de política econômica que parece advir da comparação dos dados brasileiros com os dos demais países dos BRIC parecem ser a de que a política econômica deve ir além da perseguição da estabilidade macroeconômica, priorizando a transformação da estrutura produtiva em favor de produtos mais sofisticados e, portanto, com maior elasticidade renda da demanda. É de se esperar que, uma vez implantadas medidas neste campo, a consequente folga externa permita combinar os instrumentos de gestão da demanda agregada de forma a evitar um trade-off forte entre crescimento e estabilidade macro. 


\section{REFERÊNCIAS}

BAUMANN, R.; ARAÚJO, R.; FERREIRA, F. As relações comerciais do Brasil com os demais BRICs. In: O Brasil e os demais BRICs: Comércio e Política. Brasília, DF: CEPAL. Escritório no Brasil/IPEA, 2010.

CANUTO, O. Brasil e Coréia do Sul: os (Des)caminhos da Industrialização Tardia. São Paulo: Editora Nobel, 1994.

CARLIN, W.; SOSKICE, D. Macroeconomics: Imperfections, institutions and policies. Oxford: Oxford University Press, 2006.

CARVALHO, V. S. Evolução das exportações e de seus determinantes nos BRICS (Brasil, Rússia, Índia, China e África do Sul), nas últimas três décadas. 2009. Dissertação (Mestrado em Economia) - Universidade Federal de Uberlândia, Uberlândia-MG, 2009.

COUTINHO, L. Coreia do Sul e Brasil: paralelos, sucessos e desastres. In: FIORI, J. L. (org.). Estados e moedas no desenvolvimento das nações. Petrópolis-RJ: Vozes, 1999.

DASGUPTA, S.; SINGH, A. Manufacturing, services and premature deIndustrialization in developing countries: a kaldorian empirical analysis. 2006. (Não publicado)

FEIJÓ, C. A.; CARvalHO, P. G. M. Uma interpretação sobre a evolução da produtividade industrial no Brasil nos anos noventa e as leis de Kaldor. Nova Economia, Belo Horizonte, jul./dez. 2002.

FIORI, J.L. A nova geopolítica das nações e o lugar da Rússia, China, Índia, Brasil e África do Sul. Oikos, Rio de Janeiro, v. 6, n. 2, 2007.

FLIGENSPAN, F. B. O comércio exterior da indústria brasileira no período 1999-2005. 2009. Tese (Doutorado em Economia) - Universidade Federal do Rio Grande do Sul. Porto Alegre, 2009.

FREITAS, F. Uma análise crítica do modelo kaldoriano de crescimento liderado pelas exportações. In: ENCONTRO NACIONAL DE ECONOMIA - ANPEC, 31. Porto Seguro, 2003. Anais..., Porto Seguro: UFF, 2003.

FREITAS, F. Uma Análise da Evolução das Idéias de Kaldor sobre o Processo de Crescimento Econômico. 2002. Tese de doutorado - Instituto de Economia, Universidade Federal do Rio de Janeiro, Rio de Janeiro, 2002. (Não publicada)

FUNDO MONETÁRIO INTERNACIONAL. World Economic Outlook 2014. Disponível em: <http://www.imf.org/external/Pubs/ft/weo/2014/01/>. Acesso em: 17 jul. 2014. 
FURTADO, C. Teoria e Política do Desenvolvimento Econômico. São Paulo: Abril Cultural, 1983.

Desenvolvimento e subdesenvolvimento. Rio de Janeiro: Fundo de Cultura, 1961.

HARROD, R. F. An essay in dynamic theory. The Economic Journal, n. XLIX, Mar. 1939.

HICKS, J, R. A contribution to the Theory of the Trade Cycle. Oxford University Press, 1950.

IBGE - Instituto Brasileiro de Geografia e estatística. Disponível em: <https:// www.ibge.gov.br/>. Acesso em: 27 jul. 2017.

JONES, C. Introdução à teoria do crescimento econômico. Rio de Janeiro: Campus, 2000.

KALDOR, N. The case for regional policies. Scottish Journal of Political Economy, nov. 1970.

LASTRES, H. M. M. et al. Projeto BRICS: estudo comparativo dos Sistemas de Inovação no Brasil, Rússia, Índia, China e África do Sul, 2007. Disponível em: <www. redesist.ie.ufrj.br>. Acesso em: 15 set. 2012.

LEÃO, R. P. E.; OLIVEIRA, I. T. M. Comércio exterior e política comercial indiana em análise. In: SILVA, L. A.; LEÃO, R. P. F.; HIRATUKA, C (Org.). Comércio Internacional: aspectos teóricos e a experiência indiana e chinesa. Brasília: IPEA, 2010.

MADDISON, A. The World Economy: Historical Statistical. Organization for Economic Co-operation and Development. Development Centre, Source OECD, 2001.

MEDEIROS, C. A. O ciclo recente de crescimento chinês e seus desafios. In: Observatório da economia global, n. 3, jun. 2010.

Desenvolvimento econômico e expansão nacional: rupturas e transições na Rússia e na China. In: FIORI, J. L.; MEDEIROS, C. A.; SERRANO, F. O mito do colapso do poder americano. Rio de Janeiro: Record, 2008.

China: entre os séculos XX e XXI. In: FIORI, J. L. (Org.). Estados e moedas no desenvolvimento das nações. Petrópolis-RJ: Vozes, 1999.

MYRDAL, G. Economic Theory and Underdeveloped Regions. Londres: Duckworth, 1957. Tradução para português: Teoria econômica e regiões subdesenvolvidas. Rio de Janeiro: Saga, 1965.

OCAMPO, J. A.; JOMO, K. S.; VOS, R. Explaining Growth Divergence. In: 
OCAMPO, J. A.; JOMO, K. S.; VOS, R. (Ed.). Growth Divergences. Londres: Zed Books, 2007.

PREBISCH, R. El desarrollo económico de América Latina y sus principales problemas. Santiago do Chile: Comissão Econômica para a América Latina e o Caribe (Cepal), 1949.

RICARDO, D. Princípios de Economia Política e Tributação. Lisboa: Fundação Calouste Gulbenkian, 1965.

SINGER, H. The Distribution of Gains Between Investing and Borrowing Countries. American Economic Review, v. 40, n. 2, May 1950.

SMITH, A. A riqueza das nações: investigação sobre suas naturezas e suas causas. 2. ed. São Paulo: Nova Cultural, 1985.

SOLOW, R. A contribution to the theory of economic growth. The Quarterly Journal of Economics, p. 65-94, 1956.

THE ECONOMIST. Emerging Economies: The Great Deceleration. 2013. Disponível em: < https://www.economist.com/news/leaders/21582256-emergingmarket-slowdown-not-beginning-bust-it-turning-point $>$. Acesso em: 27 jul. 2013.

THIRLWALL, A. P. A natureza do crescimento econômico: um referencial alternativo para compreender o desempenho das nações. Brasília: IPEA, 2005.

The estate of Nicholas Kaldor. New York: Cambridge University Press, 1996.

The balance of payments constraint as an explanation of international growth rates differences. Banca Nazionale del Lavoro Quarterly Review, v. 128, 1979.

UNCTAD - United Nations Conference on Trade and Development. 2013. Disponível em: <http://unctadstat.unctad.org/EN/>. Acesso em: 25 jul. 2013.

UNDP - United Nations Development Programme. Human Development Report 2013. Disponível em:< http://www.undp.org>. Acesso em: 17 jul. 2014. 
